\title{
Multicenter retrospective and comparative study of 5-minute versus 15-second endoscopic papillary balloon dilation for removal of bile duct stones
}

\section{(๑) $\circledast \ominus$}

\author{
Authors \\ Ryunosuke Hakuta ${ }^{1,2}$, Tsuyoshi Hamada ${ }^{1,3}$, Yousuke Nakai ${ }^{1}$, Hiroyuki Isayama ${ }^{1}$, Hirofumi Kogure ${ }^{1}$, Suguru Mizuno ${ }^{1}$, \\ Takahara Naminatsu', Hiroshi Yagioka ${ }^{4}$, Osamu Togawa ${ }^{5}$, Saburo Matsubara ${ }^{1}$, Yukiko Ito², Natsuyo Yamamoto ${ }^{6}$, \\ Takeshi Tsujino ${ }^{2,7}$, Kazuhiko Koike ${ }^{1}$
}

Institutions

1 Department of Gastroenterology, Graduate School of Medicine, The University of Tokyo, Tokyo, Japan

2 Department of Gastroenterology, Japanese Red Cross Medical Center, Tokyo, Japan

3 Department of Medical Oncology, Dana-Farber Cancer Institute and Harvard Medical School, Boston, MA, USA

4 Department of Gastroenterology, Tokyo Metropolitan Police Hospital, Tokyo, Japan

5 Department of Gastroenterology, Kanto Central Hospital, Tokyo, Japan

6 Department of Gastroenterology, Toshiba General Hospital, Tokyo, Japan

7 Division of Gastroenterology and Hepatology, H.H. Chao Comprehensive Digestive Disease Center, University of California, Irvine School of Medicine, CA, USA

submitted 2.3.2017

accepted after revision 24.7.2017

\section{Bibliography}

DOI https://doi.org/10.1055/s-0043-118479 |

Endoscopy International Open 2017; 05: E1027-E1034

(c) Georg Thieme Verlag KG Stuttgart · New York ISSN 2364-3722

\section{Corresponding author}

Hiroyuki Isayama, MD PhD, Department of

Gastroenterology, Graduate School of Medicine, The

University of Tokyo, 7-3-1 Hongo Bunkyo-ku, Tokyo,

Japan 113-8655

Fax: +81-3-58009801

isayama-tky@umin.ac.jp

\section{ABSTRACT}

Background and study aims Endoscopic papillary balloon dilation (EPBD) is a method of bile duct stone removal that has a better long-term outcome but a high risk of postERCP pancreatitis (PEP). Recent studies have suggested that 5-minute EPBD can reduce the incidence of PEP. This study aimed to examine the safety and effectiveness of longer duration EPBD compared with shorter duration EPBD (5 minutes vs. 15 seconds after disappearance of the waist of a dilation catheter).

Patients and methods Patients without a history of endoscopic sphincterotomy or EPBD who underwent EPBD to remove bile duct stones were selected retrospectively from five centers. The incidence of PEP, other early adverse events, and outcomes of EPBD were compared between the groups. A multivariable analysis of risk factors for PEP was performed.

Results A total of 607 patients (157 and 450 in the 5-minute and 15-second EPBD groups, respectively) were included. There were no statistically significant differences between the groups in terms of the incidence of PEP $18.3 \%$ and $8.9 \%$ in the 5 -minute and 15 -second EPBD groups, respectively; $P=0.871)$ and the incidence of overall early adverse events $(P=0.999)$. Although 5 -minute EPBD elongated the procedure time ( 45 vs. 37 minutes, $P<0.001$ ), it increased the rate of complete stone removal during a single session $(P<0.001)$ and decreased the use of lithotripsy $(P<0.001)$.

Conclusions Compared with 15-second EPBD, 5-minute EPBD did not reduce the incidence of PEP.

\section{Introduction}

Endoscopic sphincterotomy (EST) is the current standard procedure for removal of bile duct stones during endoscopic retrograde cholangiopancreatography (ERCP) [1] but is associated with adverse events such as bleeding and perforation, which can be serious [2]. Endoscopic papillary balloon dilation (EPBD) was first reported in 1983 as an alternative to EST [3]. Although EPBD has been shown to have similar effectiveness for small stones, it is not widely used because of the high risk 
of post-ERCP pancreatitis (PEP) [4-9]. EPBD is now performed only in patients with a high risk of post-EST bleeding, such as those with liver cirrhosis, those on dialysis, or those taking antithrombotic agents [10-13]. Recently, improved long-term outcomes after EPBD cast light on this procedure once again. EPBD has been reported to reduce the incidence of bile duct stone recurrence, cholangitis, and cholecystitis compared with EST $[14,15]$, presumably due to preserved sphincter of Oddi function and prevention of resultant continuous duodenobiliary reflux [16-18].

EPBD not only has a good long-term outcome, it can also help to reduce the incidence of PEP by changing the duration of EPBD. A recent randomized controlled trial (RCT) and subsequent meta-analysis suggested that 5-minute EPBD might reduce the risk of PEP to as low as that for EST [19, 20]; however, our previous data suggested that 15 -second EPBD was associated with a lower incidence of PEP compared with 2-minute EPBD, although this discrepancy could be due to different pressure applications [21-23]. Despite the potential effectiveness of 15-second EPBD suggested in our previous study, a RCT and meta-analysis have implicated the effectiveness of quite long duration EPBD (5-minute EPBD). Therefore, there is a great need to evaluate our conventional 15-second EPBD and 5-minute EPBD. The current study was performed to evaluate the safety and effectiveness of 5-minute EPBD for bile duct stone removal compared with conventional 15-second EPBD.

\section{Patients and methods}

\section{Study design}

This multicenter retrospective study was performed to evaluate the safety and effectiveness of 5-minute EPBD for endoscopic removal of bile duct stones compared with 15-second EPBD. PEP risk factors were evaluated using univariable and multivariable analyses.

Written informed consent for the procedure and use of data was obtained from each patient in accordance with the Declaration of Helsinki. This study was approved by the institutional review board in each institution.

\section{Study outcomes}

The primary end point of this study was the incidence of PEP associated with EPBD. Secondary end points included early (within 30 days of the procedure) adverse events and effectiveness of EPBD for stone removal indicated by the technical success of EPBD, successful complete stone removal during a single session, use of lithotripsy, and procedure duration during the first session.

Adverse events associated with ERCP were defined and graded according to the American Society for Gastrointestinal Endoscopy lexicon for endoscopic adverse events [24]. PEP was defined as abdominal pain along with an increase in serum amylase levels of more than threefold the upper limit of the normal range at each institution. All patients were hospitalized at least one night, and blood tests were performed routinely 18-24 hours after the procedure. We performed computed tomography for all those cases to evaluate the presence and de- gree of inflammation of the pancreas. The severity of PEP was graded as follows: mild, requiring fasting and treatment for $\leq 3$ days; moderate, requiring fasting and treatment for 4 to 10 days; and severe, requiring fasting and treatment for $>10$ days, admission to the intensive care unit for $>1$ night, or surgical intervention.

\section{Patients}

Data were collected for consecutive patients who underwent EPBD to remove bile duct stones at one academic center and four affiliated hospitals between July 2008 and September 2014. Our previous study [22] has shown that 2-minute EPBD appears to be associated with a higher risk of PEP compared with 15-second EPBD. Therefore, from July 2008 until June 2013, 15-second EPBD was performed. When the RCT was reported [20], we introduced 5-minute EPBD into clinical practice from July 2013. Exclusion criteria were as follows: (1) a history of EST or EPBD, (2) precut sphincterotomy or EST combined with EPBD, (3) large balloon dilation (balloon diameter $>10 \mathrm{~mm}$ ), (4) active pancreatitis at the time of EPBD, and (5) altered surgical anatomy with Roux-en-Y or Billroth-II reconstructions.

\section{Procedure and techniques}

A side-viewing duodenoscope (JF-240, JF-260V, or TJF-260V; Olympus, Tokyo, Japan) was inserted under moderate sedation using intravenous diazepam and pethidine hydrochloride or pentazocine hydrochloride. Wire-guided cannulation (WGC) was attempted under fluoroscopic guidance using a cannula (ERCP catheter; MTW Endoskopie, Wesel, Germany) or a sphincterotome (CleverCut3; Olympus or Autotome; Boston Scientific Japan, Tokyo, Japan) with a 0.035-inch standard guidewire (RevoWave; Piolax, Kanagawa, Japan or Jagwire; Boston Scientific Japan) or a 0.035-inch hydrophilic guidewire (Radifocus; Terumo, Tokyo, Japan). During the WGC, a guidewire was manipulated by an assistant physician with expertise in ERCP. Contrast injection was performed after several attempts at WGC at the discretion of endoscopists. After selective biliary cannulation was achieved, we performed a cholangiogram to confirm the bile duct stones and measure the bile duct diameter. The shortest diameter of the largest stone was recorded as the stone diameter, assuming that stones could be removed by prudent procedures if the shortest diameter was smaller than the diameter of the lower bile duct. A balloon catheter (Hurricane RX; Boston Scientific Japan) matched to the diameter of the lower bile duct $(\leq 10 \mathrm{~mm})$ was positioned across the papilla and inflated gradually ( 0.5 atmospheres per $\sim 15$ seconds) under fluoroscopic guidance until the waist of the balloon disappeared. After the waist had disappeared, the balloon pressure was maintained for 15 seconds or 5 minutes, and deflated immediately after that. If the waist of the balloon did not disappear after EPBD, balloon dilation was not added considering the increased risk of perforation and pancreatitis. EPBD was performed only during the first ERCP session.

Stones were removed using a 4-wire or 8-wire basket catheter and/or a retrieval balloon catheter. If the stone diameter was larger than $10 \mathrm{~mm}$ or the size of an EPBD balloon, endo- 
scopic mechanical lithotripsy (EML) was performed. In addition, we used EML when stone removal was not completed using a basket catheter. If the stones could not be fragmented successfully via EML, extracorporeal shock wave lithotripsy or electrohydraulic lithotripsy was performed in subsequent sessions. Each session was capped at approximately 60 minutes, after which an additional procedure was scheduled to reduce the risk of adverse events. Complete stone removal was confirmed by intraductal ultrasound sonography or cholangiogram using a retrieval balloon catheter. Prophylactic pancreatic stents were not used routinely. The procedure time was considered to be the time from insertion to withdrawal of the duodenoscope. ERCP procedures including biliary cannulation, EPBD, and stone removal were performed in a consistent manner across the centers. All patients were hospitalized for at least one night after the procedure. The definition of trainees was endoscopists whose experience was less than 4 years [25], and difficult cannulation was 10 attempts or 10 minutes.

\section{Statistical analysis}

The incidence of PEP with 15-second EPBD was approximately $10 \%$ in our institutions in recent years [26]. In contrast, the previous RCT and meta-analysis reported that a long duration of EPBD decreased the incidence of PEP by almost one-third compared with short duration $\operatorname{EPBD}[19,20]$. In the meta-analysis, the odds ratio of PEP for short duration EPBD compared with long duration EPBD was 3.56-3.85. Assuming the incidence of PEP with 5-minute EPBD was $2.8 \%$, the estimated sample size was 134 cases for the 5 -minute EPBD group and 402 cases for the 15 -minute EPBD respectively ( $\alpha=0.05$, power $=0.80$, sample size ratio was $1: 3$ ).

The chi-squared test or Fisher's exact test was used to evaluate univariable PEP risk factors. We used a multivariable logistic regression model to adjust for potential confounders including younger age, pancreatic duct opacification, and pancreatic stent $[20,27-29]$.

Continuous variables were expressed as medians and interquartile ranges and categorical variables as numbers and percentages of patients. Continuous variables were compared using the Wilcoxon rank sum test, and categorical variables were compared using the chi-squared test or Fisher's exact test, as appropriate.

All statistical analyses were performed using $R$ software, version 3.2.3 (R Development Core Team: http://www.r-project. org). A two-sided $P$ value $<0.05$ was considered statistically significant in all analyses.

\section{Results}

\section{Patients}

A total of 716 patients who underwent EPBD for bile duct stone removal were identified. Fifty patients with a history of Roux-en-Y or Billroth-II reconstructions and 79 patients who received endoscopic papillary large balloon dilation were excluded, leaving 607 patients in the study cohort; 157 and 450 cases underwent 5-minute EPBD and 15-second EPBD, respectively ( $\triangleright$ Fig. 1 ).
716 patients with bile duct stones without the history of EST or EPBD from July 2008 to Sept. 2014

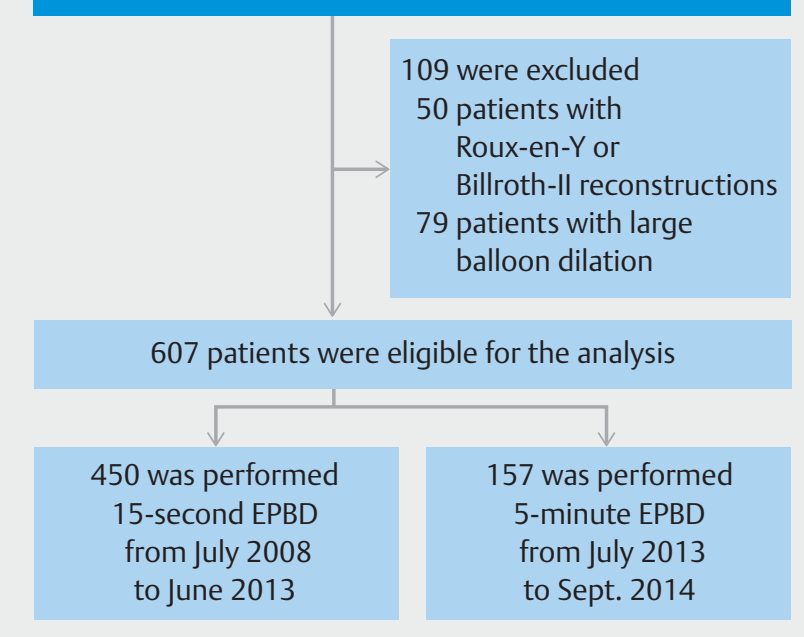

Fig. 1 Flowchart of patient selection into the 5-minute and 15-second EPBD groups for removal of bile duct stones. EPBD, endoscopic papillary balloon dilation; EST, endoscopic sphincterotomy.

The baseline characteristics of the patients are shown in - Table 1. There were statistically significant differences between the groups in the stone diameter and number of stones (5.0 vs. $6.0 \mathrm{~mm}, P=0.005$ and 1 vs. $2, P=0.050$, in the 5 -minute vs. 15 -second EPBD group, respectively). The median diameter of the lower bile duct was statistically smaller in the 5-minute EPBD group compared with the 15-second EPBD group (9.0 vs. $10.0 \mathrm{~mm}, P<0.001)$.

\section{Stone removal}

The technical success of EPBD was achieved in all 607 patients in the 5-minute and 15-second EPBD groups. The outcomes of EPBD are shown in $>$ Table 2 . The rate of complete stone removal during a single session was statistically significantly higher in the 5 -minute EPBD group ( $86.0 \%$ vs. $72.7 \%, P<0.001$, relative effect size $=13.3 \%(95 \% \mathrm{Cl}, 6.5-20.1 \%))$. In a subgroup analysis limited to the cases where the stone diameter was smaller than the EPBD balloon diameter, 5-minute EPBD was not associated with a higher rate of complete stone removal during a single session $(P=0.206)$. Although there were no statistically significant differences in the rate of overall complete stone removal, more ERCP sessions were required in the 15 -second EPBD group $(P=0.002)$. Lithotripsy was performed in $8.3 \%$ of patients in the 5-minute EPBD group and in $20.0 \%$ in the 15 second EPBD group $(P<0.001$, relative effect size $=-11.7 \%$ [95 $\% \mathrm{Cl},-17.4$ to $-6.0 \%])$. The median procedure time during the first session was statistically significantly longer in the 5 -minute EPBD group than in the 15-second EPBD group (45.0 vs. 37.0 minutes, $P<0.001)$. However, this statistically significant difference disappeared after excluding the ballooning time from the procedure time (40.0 vs. 36.7 minutes, $P=0.412$ ). 
- Table 1 Baseline characteristics of the 5-minute and 15-second EPBD for removal of bile duct stones.

\begin{tabular}{|c|c|c|c|}
\hline & $\begin{array}{l}\text { 5-minute EPBD } \\
(n=157)\end{array}$ & $\begin{array}{l}\text { 15-second EPBD } \\
(n=450)\end{array}$ & $P$ value \\
\hline Sex, male/female & $106 / 51(67.5 / 32.5)$ & $272 / 178(60.4 / 39.6)$ & 0.126 \\
\hline Age, years & $75(26-99,64-81)$ & $73.5(10-100,64-81)$ & 0.510 \\
\hline ASA-PS, $1 / 2 / 3 / 4$ & $\begin{array}{l}32 / 90 / 35 / 0 \\
(20.4 / 57.3 / 22.3)\end{array}$ & $\begin{array}{l}140 / 236 / 71 / 3 \\
(31.1 / 52.4 / 15.8 / 0.7)\end{array}$ & 0.027 \\
\hline Periampullary diverticulum & $49(31.2)$ & $182(40.4)$ & 0.045 \\
\hline Gallbladder stone & $116(73.9)$ & $274(60.9)$ & 0.004 \\
\hline Previous cholecystectomy & $17(10.8)$ & $60(13.3)$ & 0.487 \\
\hline Stone diameter, mm & $5(1-20,4-7)$ & $6(1-36,4-9)$ & 0.005 \\
\hline Number of stones & $1(1-20,1-3)$ & $2(1-36,1-3)$ & 0.050 \\
\hline Bile duct diameter, mm & $9(4-20,8-11)$ & $10(3-28,8-12)$ & $<0.001$ \\
\hline $\begin{array}{l}\text { Dilation balloon diameter, } \\
4 / 6 / 8 / 10 \mathrm{~mm}\end{array}$ & $\begin{array}{l}2 / 37 / 85 / 33 \\
(1.3 / 23.6 / 54.2 / 21.0)\end{array}$ & $\begin{array}{l}3 / 74 / 318 / 55 \\
(0.7 / 16.4 / 70.7 / 12.2)\end{array}$ & $<0.001$ \\
\hline Peak pressure of the balloon, atmospheres & $2(0.5-7,2-3)$ & $3(1-8,2-4)$ & $<0.001$ \\
\hline
\end{tabular}

- Table 2 Outcomes of the 5-minute and 15-second EPBD groups.

\begin{tabular}{|c|c|c|c|}
\hline & $\begin{array}{l}\text { 5-minute EPBD } \\
(n=157)\end{array}$ & $\begin{array}{l}\text { 15-second EPBD } \\
(n=450)\end{array}$ & $P$ value \\
\hline Use of lithotripsy & $13(8.3)$ & $90(20.0)$ & $<0.001$ \\
\hline - EML & $13(8.3)$ & $89(19.8)$ & $<0.001$ \\
\hline - ESWL & $1(0.6)$ & $2(0.4)$ & \\
\hline - EHL & $1(0.6)$ & $1(0.2)$ & \\
\hline Procedure time during the first session, minutes & $45.0(18.0-132,35.0-57.0)$ & $37.0(10.0-114,30.0-50.0)$ & $<0.001$ \\
\hline Procedure time excluding balloon time, minutes & $40.0(13.0-127,30.0-52.0)$ & $36.7(9.7-114,29.7-49.7)$ & 0.412 \\
\hline Complete stone removal during a single session & $135(86.0)$ & $327(72.7)$ & $<0.001$ \\
\hline Overall complete stone removal & $156(99.4)$ & $438(97.3)$ & 0.201 \\
\hline Number of ERCP sessions ${ }^{1}$ & & & 0.002 \\
\hline - 1 & $135(86.0)$ & $333(74.0)$ & \\
\hline .2 & $19(12.1)$ & $100(22.2)$ & \\
\hline - $\geq 3$ & $3(1.9)$ & $17(3.8)$ & \\
\hline \multicolumn{4}{|c|}{$\begin{array}{l}\text { Data are expressed as numbers and percentages of patients within a given group or as medians (range, interquartile range). EHL, electrohydraulic lithotripsy; EML, } \\
\text { endoscopic mechanical lithotripsy; EPBD, endoscopic papillary balloon dilation; ERCP, endoscopic retrograde cholangiopancreatography; ESWL, extra shock wave } \\
\text { lithotripsy. }\end{array}$} \\
\hline
\end{tabular}

The details of the stone removal procedures are summarized in $>$ Table 3. The rates of PEP risk factors such as pancreatic duct opacification [27], accidental guidewire insertion into the pancreatic duct $[30,31]$, difficult cannulation [28], and placement of prophylactic pancreatic stent $[29,32]$ were not different between the groups. However, the administration of non- steroidal anti-inflammatory drugs (NSAIDs) [33] and trainee involvement in the procedure [34] were statistically significantly higher in the 5-minute EPBD group compared with the 15-second EPBD group ( $36.8 \%$ vs. $1.3 \%, P<0.001$ and $70.4 \%$ vs. $51.2 \%, P<0.001$, respectively). 
- Table 3 Procedures in the 5-minute and 15-second EPBD groups.

\begin{tabular}{|c|c|c|c|}
\hline & $\begin{array}{l}\text { 5-minute EPBD } \\
(n=157)\end{array}$ & $\begin{array}{l}\text { 15-second EPBD } \\
(n=450)\end{array}$ & $P$ value \\
\hline Pancreatic duct opacification & $17(10.9)$ & $62(13.8)$ & 0.409 \\
\hline $\begin{array}{l}\text { Main pancreatic duct/ } \\
\text { first pancreatic branches/ } \\
\text { second pancreatic branches/ } \\
\text { acinarization }\end{array}$ & $\begin{array}{l}10 / 7 / 0 / 0 \\
(6.4 / 4.5 / 0 / 0)\end{array}$ & $\begin{array}{l}24 / 29 / 6 / 3 \\
(5.3 / 6.5 / 1.3 / 0.7)\end{array}$ & 0.498 \\
\hline Guidewire insertion into the pancreatic duct ${ }^{1}$ & $63(41.7)$ & $154(40.5)$ & 0.845 \\
\hline $\begin{array}{l}\text { Number of guidewire insertions into the pancreatic duct } \\
\text { (in cases of guidewire insertion) }{ }^{1}\end{array}$ & $2(1-10,1-5)$ & $2(1-40,1-4)$ & 0.722 \\
\hline $\begin{array}{l}\text { Difficult cannulation } \\
(\geq 10 \text { times or } \geq 10 \text { minutes })^{1}\end{array}$ & $34(23.3)$ & $105(26.4)$ & 0.507 \\
\hline ERCP performed by trainees & $107(70.4)$ & $230(51.2)$ & $<0.001$ \\
\hline NSAIDs & $56(36.8)$ & $6(1.3)$ & $<0.001$ \\
\hline Pancreatic stent & $11(7.2)$ & $48(10.7)$ & 0.270 \\
\hline \multicolumn{4}{|c|}{$\begin{array}{l}\text { Data are expressed as numbers and percentages of patients within a given group or as medians (range, interquartile range). EPBD, endoscopic papillary balloon } \\
\text { dilation; ERCP, endoscopic retrograde cholangiopancreatography; NSAIDs, nonsteroidal anti-inflammatory drugs. } \\
1 \text { Data on } 76 \text { guidewire insertions into the pancreatic duct (6 in } 5 \text {-minute EPBD group and } 70 \text { in } 15 \text {-second EPBD group, respectively) and } 63 \text { difficult cannulations } \\
\text { (11 in } 5 \text {-minute EPBD group and } 52 \text { in } 15 \text {-second EPBD group, respectively) were missing. }\end{array}$} \\
\hline
\end{tabular}

\section{PEP and other early adverse events}

Early adverse events are shown in $>$ Table 4 . There was no statistically significant difference in terms of the incidence of PEP (8.3\% and $8.9 \%$ in the 5-minute and 15 -second EPBD groups, respectively; $P=0.871$, relative effect size $=-0.6 \%(95 \% \mathrm{Cl},-5.7$ to $4.4 \%)$ ), and the incidences of severe PEP $(1.9 \%$ and $0.4 \%$, respectively; $P=0.112$, relative effect size $=1.5 \%(95 \% \mathrm{Cl},-0.8$ to $3.7 \%)$ ). The association between PEP and EPBD groups did not alter materially after adjustment for multiple potential confounders including younger age, pancreatic duct opacification, and pancreatic stent ( $\nabla$ Table $\mathbf{5}$ and $\triangleright$ Table $\mathbf{6}$ ). In a secondary analysis limited to patients who did not receive NSAIDs or a pancreatic stent, we did not find a statistically significant difference. The incidence of PEP was $7.4 \%$ in the 5-minute EPBD group and $7.6 \%$ in the 15 -second EPBD group, respectively $(P=$ 0.999). However, the incidence of PEP tended to be higher in the 15 -second EPBD group in patients who received NSAIDs or a pancreatic stent $(9.7 \%$ vs $18.5 \%, P=0.188)$. All patients with PEP were managed conservatively without the need for further interventions. The overall rate of early adverse events was not different between the groups (13.4\% and $13.1 \%$ in the 5 -minute and 15 -second EPBD groups, respectively; $P=0.999)$. Moderate bleeding was observed in one patient $(0.2 \%)$ in the 15 -second EPBD group. One patient in each group developed retroperitoneal perforation, but this was managed conservatively.

\section{Discussion}

This retrospective cohort study was performed to evaluate the safety and effectiveness of 5-minute EPBD compared with 15second EPBD for bile duct stone removal. In this study, 5-minute EPBD did not reduce PEP, in contrast to previous reports
$[19,20]$, or the overall incidence of early adverse events. The use of lithotripsy was reduced and the prospect of complete stone removal in a single session was improved after 5 -minute EPBD. The procedure time was 8 minutes longer in the 5 -minute EPBD group than in the 15-second EPBD group.

We did not find a statistically significant difference in the incidence of PEP between the 5-minute and 15-second EPBD groups $(8.3 \%$ vs. $8.9 \%, P=0.871)$. Although the multivariable analysis revealed pancreatic opacification as a risk factor for PEP, there was no relationship between PEP and the EPBD groups, in this study. However, accumulating evidence indicates that a longer duration of EPBD can reduce the incidence of PEP. In a RCT of 5-minute vs. 1-minute EPBD [20], the incidence of PEP was statistically significantly lower in the 5-minute EPBD group than in the 1 -minute EPBD group ( $4.8 \%$ vs. $15.1 \% ; P=0.038$ ). The investigators speculated that adequate dilation of the papilla via EPBD over a longer duration could facilitate subsequent stone removal procedures and mitigate damage to the ampulla. Based on this RCT, a subsequent meta-analysis comparing EPBD and EST showed superiority of long duration over short duration EPBD and even over EST in terms of early adverse events [19]. Despite these promising results, we failed to demonstrate the superiority of 5-minute EPBD in terms of PEP. A trend toward a lower incidence of PEP in the 5-minute EPBD group among patients who received a pancreatic stent or NSAIDs may suggest the potential effectiveness of 5-minute EPBD in prevention of PEP in high risk patients, but statistical power was limited.

In the previous RCT, a 10-mm EPBD balloon was used in all cases contrary to our study in which the size of dilation balloon was matched to the lower bile duct [20]. Although the low-degree dilation of the biliary orifice using a smaller balloon cathe- 
Dable 4 Short-term adverse events in the 5-minute and 15-second EPBD groups.

\begin{tabular}{|c|c|c|c|}
\hline & $\begin{array}{l}\text { 5-minute EPBD } \\
(n=157)\end{array}$ & $\begin{array}{l}\text { 15-second EPBD } \\
(n=450)\end{array}$ & $P$ value \\
\hline Overall & $21(13.4)$ & $59(13.1)$ & 0.999 \\
\hline Pancreatitis $^{1}$ & $13(8.3)$ & $40(8.9)$ & 0.871 \\
\hline - Mild/moderate/severe & $\begin{array}{l}10 / 0 / 3 \\
(6.4 / 0 / 1.9)\end{array}$ & $\begin{array}{l}29 / 9 / 2 \\
(6.4 / 2.0 / 0.4)\end{array}$ & 0.091 \\
\hline Cholangitis & $4(2.5)$ & $14(3.1)$ & 0.999 \\
\hline Cholecystitis & $5(3.2)$ & $4(0.9)$ & 0.543 \\
\hline Aspiration pneumonia & $1(0.6)$ & $4(0.9)$ & 0.999 \\
\hline Liver abscess & $1(0.6)$ & $1(0.2)$ & 0.451 \\
\hline Bleeding & 0 & $1(0.2)$ & 0.999 \\
\hline Retroperitoneal perforation & $1(0.6)$ & $1(0.2)$ & 0.451 \\
\hline Basket impaction & 0 & 0 & NA \\
\hline
\end{tabular}

- Table 5 Univariable analysis of risk factors for PEP.

\begin{tabular}{|c|c|c|c|}
\hline & \multicolumn{3}{|c|}{ Univariable } \\
\hline & OR & $95 \% \mathrm{Cl}$ & $P$ value \\
\hline Younger age (<50 y) & 1.07 & $0.32-2.87$ & 0.803 \\
\hline Female sex & 1.41 & $0.76-2.58$ & 0.239 \\
\hline Periampullary diverticulum & 1.17 & $0.63-2.15$ & 0.657 \\
\hline Bile duct diameter $<10 \mathrm{~mm}$ & 1.12 & $0.61-2.05$ & 0.773 \\
\hline Stone diameter $>10 \mathrm{~mm}$ & 1.19 & $0.43-2.80$ & 0.654 \\
\hline Number of stones $>3$ & 1.97 & $1.00-3.76$ & 0.033 \\
\hline Dilation balloon diameter $<10 \mathrm{~mm}$ & 0.81 & $0.37-1.97$ & 0.545 \\
\hline Peak pressure of the balloon $>4$ atmospheres & 0.66 & $0.13-2.16$ & 0.608 \\
\hline 5-minute EPBD & 0.93 & $0.44-1.83$ & 0.871 \\
\hline Procedure time $<30$ minutes & 0.82 & $0.35-1.71$ & 0.728 \\
\hline Lithotripsy & 1.00 & $0.42-2.17$ & 0.999 \\
\hline Complete stone removal during a single session & 0.97 & $0.49-2.04$ & 0.999 \\
\hline ERCP performed by trainees & 1.45 & $0.78-2.76$ & 0.247 \\
\hline Difficult cannulation ( $\geq 10$ times or $\geq 10$ minutes) & 1.91 & $0.98-3.63$ & 0.041 \\
\hline Pancreatic duct opacification & 3.01 & $1.45-5.98$ & 0.002 \\
\hline Guidewire insertion into the pancreatic duct & 2.11 & $1.14-3.96$ & 0.012 \\
\hline Number of guidewire insertions into the pancreatic duct $>3$ times & 2.06 & $0.72-5.14$ & 0.104 \\
\hline NSAIDs & 1.12 & $0.38-2.80$ & 0.812 \\
\hline Pancreatic stent & 2.36 & $0.99-5.15$ & 0.029 \\
\hline
\end{tabular}


- Table 6 Multivariable analysis of risk factors for PEP.

\begin{tabular}{|l|l|l|l|}
\hline & Multivariable & $\mathbf{P}$ value \\
\hline 5-minute EPBD & OR & $\mathbf{9 5 \% C l}$ & 0.948 \\
\hline Younger age $(<50$ y) & 1.02 & $0.50-1.99$ & 0.933 \\
\hline Pancreatic duct opacification & 1.04 & $0.39-2.78$ & 0.006 \\
\hline Pancreatic stent & 2.64 & $1.31-5.29$ & 0.216 \\
\hline Cl, confidence interval; EPBD, endoscopic papillary balloon dilation; OR, odds ratio; PEP, post-ERCP pancreatitis. & $0.74-3.75$ & \\
\hline
\end{tabular}

ter might have driven our findings toward null, the diameter of a dilation balloon catheter was not associated with a higher incidence of PEP in our univariable analysis. Nonetheless, a further investigation using endoscopic papillary large balloon dilation with a> 12-mm balloon is warranted. We also thought that the cause of PEP after EPBD is attributed to damage to the ampulla, and which was mainly caused by stone extraction through the narrow opening after EPBD. To date, we have sought the usefulness of EPBD for stone extraction and are familiar with the stone extraction procedure after EPBD: gentle stone extraction along the distal bile duct axis, the use of EML for large stones, and shortening the procedure duration to reduce excessive damage to the papilla [21-23]. Hence, the superiority of 5-minute EPBD in terms of PEP might have been attenuated by these experiences, but the relatively wide opening after 5 minute EPBD can be helpful to those endoscopists who are accustomed to EST only.

Regarding the effectiveness of the procedure, the incidence of complete stone removal during a single session was higher and the use of lithotripsy was lower in the 5-minute EPBD group. However, owing to the chronological aspect of our EPBD database, cases of large and multiple stones, which were eligible for large balloon dilation in recent years, were contained in the 15 -second EPBD group. The differences in those baseline characteristics influenced the preferable effectiveness of the 5-minute EPBD group in this study. As shown in our previous study on 10-mm EPBD [26], a wide papillary opening due to adequate dilation after EPBD can facilitate stone removal and furthermore, can reduce the need for lithotripsy. A sufficiently enlarged orifice of the bile duct potentially eases insertion of endoscopic devices and subsequent stone removal. However, we believe the major advantage of EPBD is better long-term outcomes due to the preserved function of the sphincter of Oddi. Therefore, a large prospective study with longer follow-up data is warranted to validate the role of long-duration EPBD in stone removal.

While the involvement of multiple endoscopists is advantageous in terms of the generalizability of our data, the results should be interpreted with caution. As we discussed above, EPBD has been the major procedure used for stone extraction in our centers until recently, and the attending physicians were familiar with stone extraction procedures after EPBD. Gentle manipulation of devices for stone extraction is mandatory to prevent ampullary edema and subsequent PEP after
EPBD because of the small opening of the ampulla. Endoscopists who are used to stone extraction only after EST may prefer 5-minute EPBD.

There are some limitations to be acknowledged in this study. First, there were between-group differences in patient and procedural characteristics due to the retrospective nature of this study. Inherent bias was still possible even after the multivariable analysis for the risk factors of PEP. A prospective RCT is warranted to evaluate the superiority of 5-minute EPBD. Second, there was a statistically significant difference in the administration rate of NSAIDs between the groups $(36.8 \%$ vs. $1.3 \%$ in the 5 -minute and 15 -second EPBD groups, respectively; $P<0.001)$. Controversy still exists with regard to the routine use of NSAIDs [35], but at least no data have suggested that NSAIDs adversely affect the safety or effectiveness of ERCP. In addition, because 5-minute EPBD was introduced into clinical practice later than 15-second EPBD, the learning curve effects for the 5minute EPBD procedure should be considered. However, apart from the duration time, the procedures could be carried out in the same manner and therefore, we believe that the influence of less expertise in 5-minute EPBD on our findings might be minimal. Finally, the negative results of our study could have been due to the relatively small sample size, although our sample size calculation supported the view that the size of our study population might have been sufficient.

In conclusion, our study did not support the superiority of 5minute EPBD over 15-second EPBD in terms of prevention of PEP. Although 5-minute EPBD appeared to facilitate complete stone removal with less frequent use of lithotripsy and a smaller number of ERCP sessions, further evidence is required before implementing 5-minute EPBD in clinical practice.

\section{Acknowledgements}

We are deeply grateful to the following colleagues for copyediting this study and for helpful advice: Dr Yukihiro Koike (Department of Gastroenterology, Kanto Central Hospital, Tokyo, Japan), Dr Masahiro Arai (Department of Gastroenterology, Toshiba General Hospital, Tokyo, Japan), Dr Keiji Ogura (Department of Gastroenterology, Tokyo Metropolitan Police Hospital, Tokyo, Japan), and Dr Ryo Nakata (Department of Gastroenterology, Japanese Red Cross Medical Center, Tokyo, Japan). 
Competing interests

None

References

[1] Vaira D, D’Anna L, Ainley C. Endoscopic sphincterotomy in 1000 consecutive patients. Lancet 1989; 19: $431-434$

[2] Freeman ML, Nelson DB, Sherman S et al. Complications of endoscopic biliary sphincterotomy. NEJM 1996; 335: 909-918

[3] Staritz M, Ewe K, Meyer zum Buschenfelde KH. Endoscopic papillary dilation (EPD) for the treatment of common bile duct stones and papillary stenosis. Endoscopy 1983; 15: 197-198

[4] Minami A, Nakatsu T, Uchida N et al. Papillary dilation vs sphincterotomy in endoscopic removal of bile duct stones. A randomized trial with manometric function. Dig Dis Sci 1995; 40: 2550 - 2554

[5] Bergman JJ, Rauws EA, Fockens P et al. Randomised trial of endoscopic balloon dilation versus endoscopic sphincterotomy for removal of bileduct stones. Lancet 1997; 349: 1124-1129

[6] Ochi Y, Mukawa K, Kiyosawa K. Comparing the treatment outcomes of endoscopic papillary dilation and endoscopic sphincterotomy for removal of bile duct stones. J Gastroenterol Hepatol 1999; 14: 90 - 96

[7] Fujita N, Maguchi H, Komatsu Y et al. Endoscopic sphincterotomy and endoscopic papillary balloon dilatation for bile duct stones: A prospective randomized controlled multicenter trial. Gastrointest Endosc 2003; 57: $151-155$

[8] Vlavianos P, Chopra K, Mandalia S. Endoscopic balloon dilatation versus endoscopic sphincterotomy for the removal of bile duct stones: a prospective randomised trial. Gut 2003; 52: 1165-1169

[9] Disario JA, Freeman ML, Bjorkman DJ et al. Endoscopic balloon dilation compared with sphincterotomy for extraction of bile duct stones. Gastroenterology 2004; 127: 1291-1299

[10] Kawabe T, Komatsu Y, Tada M et al. Endoscopic papillary balloon dilation in cirrhotic patients: removal of common bile duct stones without sphincterotomy. Endoscopy 1996; 28: 694-698

[11] Takahara N, Isayama H, Sasaki T et al. Endoscopic papillary balloon dilation for bile duct stones in patients on hemodialysis. J Gastroenterol 2012; 47: $918-923$

[12] Park DH, Kim M-H, Lee SK et al. Endoscopic sphincterotomy vs. endoscopic papillary balloon dilation for choledocholithiasis in patients with liver cirrhosis and coagulopathy. Gastrointest Endosc 2004; 60: $180-185$

[13] Hamada T, Yasunaga H, Nakai Y et al. Bleeding after endoscopic sphincterotomy or papillary balloon dilation among users of antithrombotic agents. Endoscopy 2015; 47: $997-1004$

[14] Yasuda I, Fujita N, Maguchi H et al. Long-term outcomes after endoscopic sphincterotomy versus endoscopic papillary balloon dilation for bile duct stones. Gastrointest Endosc 2010; 72: 1185-1191

[15] Doi S, Yasuda I, Mukai T et al. Comparison of long-term outcomes after endoscopic sphincterotomy versus endoscopic papillary balloon dilation: a propensity score-based cohort analysis. J Gastroenterol 2013; 48: 1090 - 1096

[16] Kawabe $\mathrm{T}$, Komatsu $\mathrm{Y}$, Isayama $\mathrm{H}$ et al. Histological analysis of the papilla after endoscopic papillary balloon dilation. Hepatogastroenterology 2003; 50: 919-923

[17] Isayama H, Komatsu Y, Inoue $Y$ et al. Preserved function of the Oddi sphincter after endoscopic papillary balloon dilation. Hepatogastroenterology 2003; 50: 1787-1791
[18] Yasuda I, Tomita E, Enya M et al. Can endoscopic papillary balloon dilation really preserve sphincter of Oddi function? Gut 2001; 49: $686-$ 691

[19] Liao WC, Tu YK, Wu MS et al. Balloon dilation with adequate duration is safer than sphincterotomy for extracting bile duct stones: a systematic review and meta-analyses. Clin Gastroenterol Hepatol 2012; 10: $1101-1109$

[20] Liao WC, Lee CT, Chang CY et al. Randomized trial of 1-minute versus 5-minute endoscopic balloon dilation for extraction of bile duct stones. Gastrointest Endosc 2010; 72: 1154-1162

[21] Komatsu Y, Kawabe T, Toda $\mathrm{N}$ et al. Endoscopic papillary balloon dilation for the management of common bile duct stones: experience of 226 cases. Endoscopy 1998; 30: $12-17$

[22] Tsujino $\mathrm{T}$, Kawabe $\mathrm{T}$, Isayama $\mathrm{H}$ et al. Efficacy and safety of low-pressured and short-time dilation in endoscopic papillary balloon dilation for bile duct stone removal. J Gastroenterol Hepatol 2008; 23: 867 871

[23] Tsujino T, Kawabe T, Komatsu Y et al. Endoscopic papillary balloon dilation for bile duct stone: immediate and long-term outcomes in 1000 patients. Clin Gastroenterol Hepatol 2007; 5: 130-137

[24] Cotton PB, Eisen GM, Aabakken L et al. A lexicon for endoscopic adverse events: report of an ASGE workshop. Gastrointest Endosc 2010; 71: $446-454$

[25] Kawakami H, Maguchi H, Mukai T et al. A multicenter, prospective, randomized study of selective bile duct cannulation performed by multiple endoscopists: the BIDMEN study. Gastrointest Endosc 2012; 75: $362-372,372$ e361

[26] Akiyama D, Hamada $\mathrm{T}$, Isayama $\mathrm{H}$ et al. Superiority of 10 -mm-wide balloon over 8-mm-wide balloon in papillary dilation for bile duct stones: A matched cohort study. Saudi J Gastroenterol 2015; 21: $213-219$

[27] Tsujino $\mathrm{T}$, Isayama $\mathrm{H}$, Komatsu $\mathrm{Y}$ et al. Risk factors for pancreatitis in patients with common bile duct stones managed by endoscopic papillary balloon dilation. Am J Gastroenterol 2005; 100: 38 -42

[28] Freeman ML, DiSario JA, Nelson DB et al. Risk factors for post-ERCP pancreatitis: a prospective, multicenter study. Gastrointest Endosc 2001; 54: $425-434$

[29] Ito K, Fujita N, Noda Y et al. Can pancreatic duct stenting prevent post-ERCP pancreatitis in patients who undergo pancreatic duct guidewire placement for achieving selective biliary cannulation? A prospective randomized controlled trial J Gastroenterol 2010; 45: $1183-1191$

[30] Nakai $\mathrm{Y}$, Isayama H, Sasahira N et al. Risk factors for post-ERCP pancreatitis in wire-guided cannulation for therapeutic biliary ERCP. Gastrointest Endosc 2015; 81: 119-126

[31] Sasahira N, Kawakami H, Isayama H et al. Early use of double-guidewire technique to facilitate selective bile duct cannulation: the multicenter randomized controlled EDUCATION trial. Endoscopy 2015; 47: $421-429$

[32] Choudhary A, Bechtold ML, Arif M et al. Pancreatic stents for prophylaxis against post-ERCP pancreatitis: a meta-analysis and systematic review. Gastrointest Endosc 2011; 73: 275-282

[33] Elmunzer BJ, Scheiman JM, Lehman GA et al. A randomized trial of rectal indomethacin to prevent post-ERCP pancreatitis. NEJM 2012; 366: $1414-1422$

[34] Cheng CL, Sherman S, Watkins JL et al. Risk factors for post-ERCP pancreatitis: a prospective multicenter study. Am J Gastroenterol 2006; 101: 139-147

[35] Levenick JM, Gordon SR, Fadden LL et al. Rectal indomethacin does not prevent post-ERCP pancreatitis in consecutive patients. Gastroenterology 2016; 150: 911 - 917 